\title{
Resilient Modulus Performance of Warm Mix Asphaltic Concrete using Cecabase RT Additive
}

\author{
Ahmad Kamil Arshad, Ekarizan Shaffie, Wardati Hashim, Nurul Syahirah Fatinah Mustapa, \\ Khairil Azman Masri
}

\begin{abstract}
Warm mix asphalt is an energy efficient mix that can be produced at lower temperature than the conventional hot mix asphalt, while maintaining the properties and performance required for the conventional hot mix asphalt. This paper presents a study in mix design of dense graded asphaltic concrete using a warm mix additive known as Cecabase RT. Type AC14 gradation for granite aggregates and bitumen of penetration type 60/70 were used for this study based on the Public Works Department of Malaysia's Standard Specification for Road Works. The mixing temperature for the control sample AC14 mix without the additive was set at $160^{\circ} \mathrm{C}$ while for the mix using the Cecabase RT additive, the mixing temperature was set at $135^{\circ} \mathrm{C}$. Marshall test procedure were then used to prepare the samples and volumetric properties were then evaluated to determine the optimum bitumen content. The optimum Cecabase RT additive content was then determined using samples prepared at the optimum bitumen content. The resilient modulus test was then carried out on the samples based on the repeated load indirect tensile test at temperatures of $25^{\circ} \mathrm{C}$ and $40^{\circ} \mathrm{C}$ at three different pulse repetition periods. From the analysis of the results, it was found that optimum bitumen content was at $4.9 \%$ while the optimum Cecabase RT additive content for the AC14 mix is 0.3\%. The resilient modulus values obtained for the mix using Cecabase RT warm mix additive is higher than the control samples at both test temperatures and at all the pulse repetition period tested. It can be concluded that the use of Cecabase RT additive have the advantages of reducing the mixing temperature, thus producing a more energy efficient mix while improving the stiffness of the mix in terms of resilient modulus values, thus increasing a pavement load carrying capacity.
\end{abstract}

Keywords: Cecabase RT; Marshall mix design; Resilient modulus; Volumetric properties; Warm mix asphalt

\section{INTRODUCTION}

Asphalt mixtures are classified by the temperature range at which they are produced and the strength and durability of the final product. Hot mix asphalt (HMA) are currently produced at around $160^{\circ} \mathrm{C}$ and compacted at temperatures of around $130^{\circ} \mathrm{C}$, depending on the mix type and binder grade [1]. This

Revised Manuscript Received on October 22, 2019.

* Correspondence Author

Ahmad Kamil Arshad*, Institute for Infrastructure Engineering and Sustainable Management (IIESM), Universiti Teknologi MARA, 40450 Shah Alam, Selangor, Malaysia. Email: drahmadkamil@uitm.edu.my

Ekarizan Shaffie, Institute for Infrastructure Engineering and Sustainable Management (IIESM), Universiti Teknologi MARA, 40450 Shah Alam, Selangor, Malaysia Email: ekarizan@uitm.edu.my

Wardati Hashim, Faculty of Civil Engineering, Universiti Teknologi MARA, 40450 Shah Alam, Selangor, Malaysia. Email: wardati@uitm.edu.my

Nurul Syahirah Fatinah Mustapa, Faculty of Civil Engineering, Universiti Teknologi MARA, 40450 Shah Alam, Selangor, Malaysia. Email: syeiraf@gmail.com

Khairil Azman Masri, Faculty of Civil Engineering Technology, Universiti Malaysia Pahang, Pahang, Malaysia. Email: kairilazman@ump.edu.my temperature is recommended to ensure that the binder is sufficiently fluid so that proper aggregate coating and compaction can be achieved [2]. Cold asphalt mixtures are manufactured at ambient temperatures, on the order of $20^{\circ}$ to $50^{\circ} \mathrm{C}$, using bitumen emulsion as its binder. Hot mix asphalt has higher stability and durability than cold mix asphalt, which is the reason why cold mix is used in the lower pavement layers of low-volume roadways.

There is a need to reduce the production temperature of asphalt so that energy costs can be saved. Warm Mix Asphalt (WMA) is currently being proposed as an alternative to the conventional asphalt as it can be produced at lower temperatures of about $105^{\circ} \mathrm{C}$ to $135^{\circ} \mathrm{C}$ [3]. Warm mix asphalt is produced to achieve a level of performance (e.g. strength and durability) that is equivalent to or better than hot mix asphalt [2].

There are four general categories of WMA technologies currently available for use in asphalt pavement construction. These includes organic additive products such as Sasobit and Asphaltan B, water-bearing Zeolite products such as Aspha-Min and Advera WMA, water-based foaming process products such as WAM Foam and the lastly, emulsion-based process products such as Evotherm [4].

All those technologies reduce the viscosity of the asphalt binder at a given temperature and allow the aggregate to be fully coated at lower mixing temperatures. The application of WMA can have a significant cost and environmental impact on highway projects. The asphalt mixture production and placement temperature could bring down production cost, improve the environment by lowering the harmful emissions, and improve pavement performance [5]. It was reported that the manufacturers and materials suppliers achieved energy savings in the order of $30 \%$, with a corresponding reduction in $\mathrm{CO}_{2}$ emissions of $30 \%$. The advantages of the WMA include reduced fuel cost, reduced mixing and compaction temperature, early site opening, lower plant wear, lesser aging of binder, reduced fumes and emissions, improve workability, and extended paving window [6].

Among the reported improvements in performance of asphalt mixtures using WMA additives include the increase in the stiffness of the mix in terms of resilient modulus values [7]. Resilient modulus is analogous to the modulus of elasticity (E) with both terms having the same basic theory of elasticity definition. The resilient modulus is determined from a repeated load test.

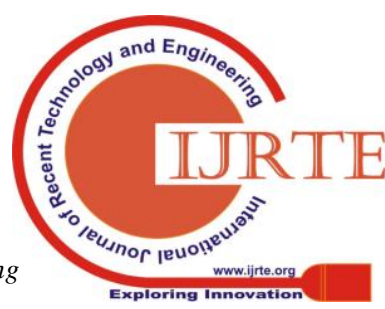


Peak values of stress and recoverable (resilient) deformation occurring in the test are used to calculate the resilient elastic constants even though peak stress and recoverable deformation do not occur at the same time in a dynamic test. The importance of resilient modulus test is to assure that the pavement achieved adequate stiffness, thus improving its load carrying capacity and also resist deformation [8].

The objective of this study is to evaluate the volumetric properties of WMA using Cecabase RT as additive and to compare the resilient modulus performance of the WMA with HMA (control samples). This is to ensure that the WMA achieved a level of stiffness that is at least equivalent to HMA.

\section{METHODOLOGY}

Laboratory work was carried out to evaluate the volumetric properties and to investigate the performance of resilient modulus for warm-mix asphalt (WMA) using binder of penetration grade $60 / 70$ with Cecabase RT additive at mixing temperature of $135^{\circ} \mathrm{C}$. Cecabase $\mathrm{RT}$ is a surfactant type, water-free additive used to produce WMA [9]. Type AC14 gradation for granite aggregates (as shown in Table 1) and bitumen of penetration type 60/70 were used for this study based on the Public Works Department of Malaysia's Standard Specification for Road Works. Marshall mix design method in accordance to ASTM D1559 was used to prepare the samples and to determine the volumetric properties and optimum binder content of the AC14 mix [10]. The volumetric properties evaluated include bulk density, voids in mineral aggregate (VMA), voids filled with asphalt (VFA) and air voids in mix (AV).

Table 1: Aggregate Gradation for AC14 Samples (PWD Malaysia, 2008)

\begin{tabular}{|c|c|}
\hline Mid Designation & AC 14 \\
\hline B.S Sieve & \% Passing By Weight \\
\hline $28.0 \mathrm{~mm}$ & - \\
$20.0 \mathrm{~mm}$ & 100 \\
$14.0 \mathrm{~mm}$ & $90-100$ \\
$10.0 \mathrm{~mm}$ & $76-86$ \\
$5.0 \mathrm{~mm}$ & $50-62$ \\
$3.35 \mathrm{~mm}$ & $40-54$ \\
$1.18 \mathrm{~mm}$ & $18-34$ \\
$425 \mu \mathrm{m}$ & $12-24$ \\
$150 \mu \mathrm{m}$ & $6-14$ \\
$75 \mu \mathrm{m}$ & $4-8$ \\
\hline
\end{tabular}

Bitumen modification was carried out by adding Cecabase RT at percentages of $1 \%$ to $3 \%$ at increments of $0.5 \%$ by weight of bitumen using a mechanical stirrer (Figure 1) to ensure adequate blending between the bitumen and Cecabase RT with the temperature controlled at $135^{\circ} \mathrm{C}$ (the stirrer was provided with a temperature control system). After the modification of the bitumen, the bitumen and aggregates were mixed and compacted at a temperature of $120^{\circ} \mathrm{C}$.

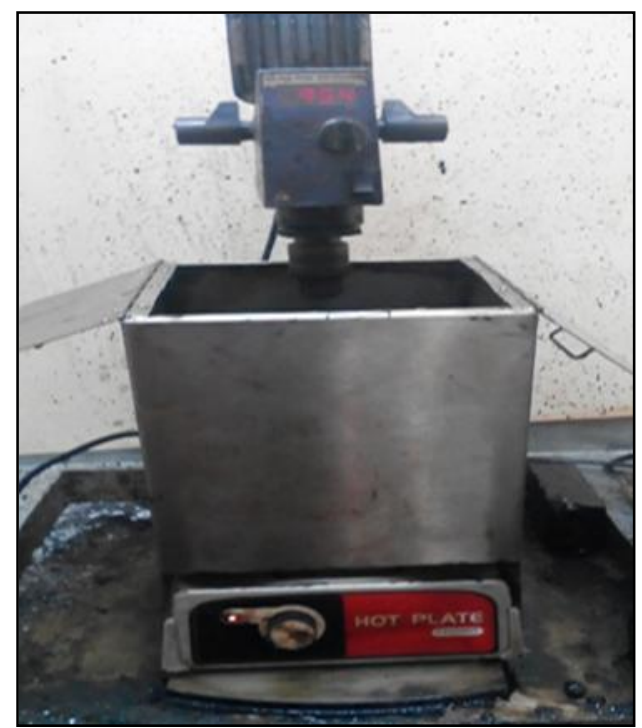

Fig. 1. Blending Cecabase RT with bitumen using mechanical stirrer

The last part of this research focused on the resilient modulus test to evaluate stiffness performance of WMA. This test was carried out to ensure that the asphalt mix achieved adequate stiffness for use as a pavement surfacing. The resilient modulus is determined from the repeated load indirect tensile test at $25^{\circ} \mathrm{C}$ and $40^{\circ} \mathrm{C}$ in accordance with ASTM D4123. Peak values of stress and recoverable (resilient) deformation occurring in the test were used to calculate the resilient modulus values.

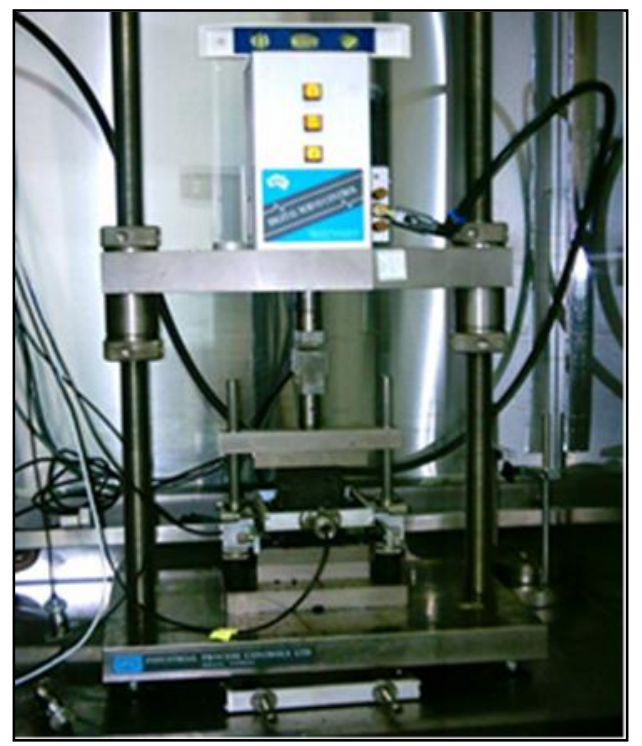

Fig. 2. Resilient Modulus Test using UTM-5P

Evaluation and analysis of the above test results will lead to the understanding of the effect of variation of WMA with the additive (Cecabase RT) on the volumetric properties and the stiffness performance of the WMA. This can be carried out by comparing the properties of the WMA with properties of the conventional HMA (control sample). 


\section{RESULTS AND DISCUSSION}

\section{A. Volumetric Properties and Marshall Test Results}

The purpose of Marshall Mix Design tests is to determine the optimum bitumen content (OBC) of the design mix for AC14 compacted using 75 blows of the Marshall hammer. Data from the Marshall test were used to plot five parameters which are Stability, Flow, Bulk Density, Voids Filled with Bitumen (VFB) and Air Voids in Mix (VIM) versus the bitumen content. The graphs of the Marshall tests are shown in Figure 3 (a) - (e).

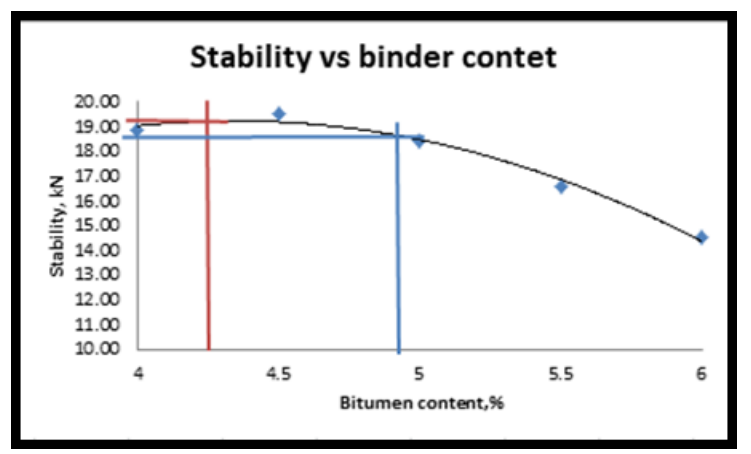

(a)

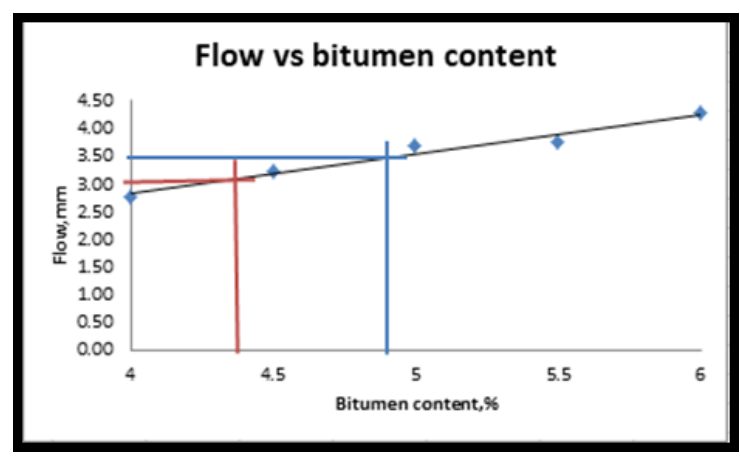

(b)

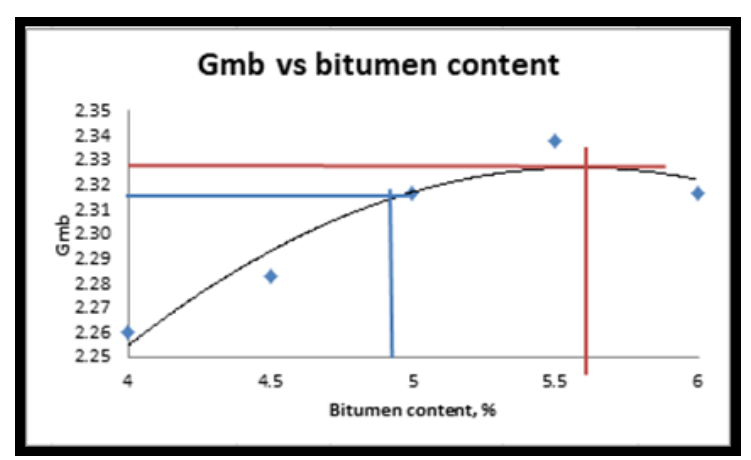

(c)

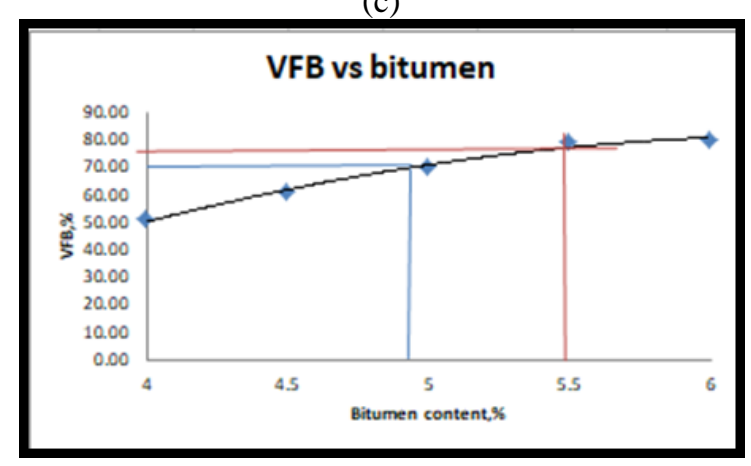

(d)

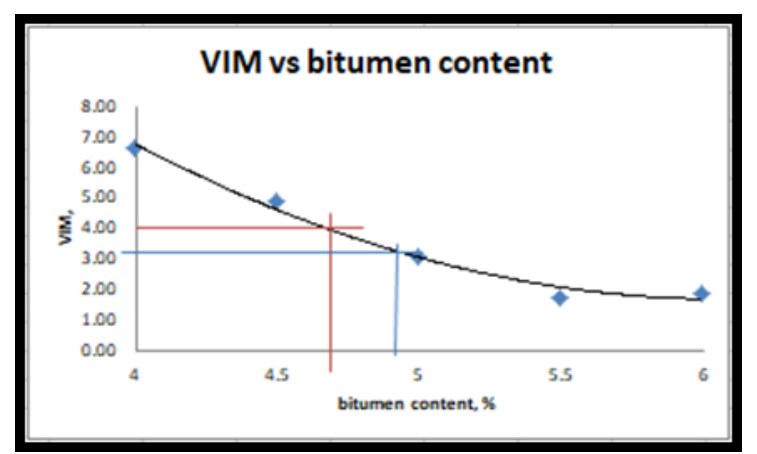

(e)

Fig. 3. Marshall test result for control (HMA) sample (Individual plot of Bitumen content versus (a) Stability, (b) Flow, (c) Bulk density, (d) Voids Filled with Bitumen and (e) Air voids.

\section{B. Optimum Bitumen Content (OBC)}

Determination of OBC for this study was obtained by referring to PWD Malaysia's method. Table 2 shows the OBC results that have been obtained from Marshall test results graph by averaging the five parameters. The OBC obtained was at $4.9 \%$ bitumen content. The values at $\mathrm{OBC}$ were checked for Stability, Flow, Bulk Density, Voids Filled with Bitumen (VFB) and Air Voids in Mix (VIM) for compliance with the PWD Malaysia's requirements.

Table 2: Determination of optimum bitumen content

\begin{tabular}{|c|c|}
\hline Parameter & Selected OBC \\
\hline Peak of stability curve & 4.25 \\
\hline Peak of bulk density curve & 5.6 \\
\hline Flow equals to 3 mm & 4.4 \\
\hline VFB equals to $75 \%$ & 5.5 \\
\hline VIM equals to $4.0 \%$ & 4.75 \\
\hline Average & 4.9 \\
\hline
\end{tabular}

\section{Optimum Cecabase Content}

Using the OBC obtained from the control sample (HMA), WMA specimens that contain Cecabase RT was prepared. The amount of Cecabase RT to be added was determined by varying the amount of Cecabase RT used at the optimum bitumen content. The amount of Cecabase RT used was $0.2 \%$, $0.25 \%, 0.3 \%, 0.35 \%$ and $0.4 \%$. The optimum amount of Cecabase RT to be used was determined at $0.3 \%$ by weight of bitumen based on the amount that complied with PWD Malaysia's specification requirements on the volumetric properties of HMA. The result is tabulated in Table 3. Figure 4 shows the optimum amount of Cecabase RT obtained from Marshall graph by averaging the five optimum cecabase RT content. The Marshall stability, flow, VFB and VIM of the WMA as shown in Table 4 complied with the PWD Malaysia's specification requirement. These parameters were obtained from the Marshall graph (Figure 4) at $0.3 \%$ Cecabase content. 
Table 3: Determination of additive content

\begin{tabular}{|c|c|}
\hline Parameters & $\begin{array}{c}\text { Cecabase Content } \\
(\mathbf{\%})\end{array}$ \\
\hline Peak of stability curve & 0.32 \\
\hline Peak of unit weight curve & 0.29 \\
\hline Flow equals to 3mm & 0.225 \\
\hline VIM equals to 4.0\% for wearing & 0.24 \\
\hline $\begin{array}{c}\text { VFB equals to 75\% for wearing } \\
\text { course }\end{array}$ & 0.39 \\
\hline Average & 0.3 \\
\hline
\end{tabular}

Table 4: Comparison of specification requirement for WMA at $0.3 \%$ Cecabase content

\begin{tabular}{|c|c|c|}
\hline Parameters & $\begin{array}{c}\text { PWD Malaysia;s } \\
\text { specification }\end{array}$ & WMA \\
\hline Marshall stability & $>8000 \mathrm{~N}$ & 15100 \\
\hline Flow & $2-4 \mathrm{~mm}$ & $3.6 \mathrm{~mm}$ \\
\hline VFB & $70-80 \%$ & 74 \\
\hline Air void (VIM) & $3-5 \%$ & $3 \%$ \\
\hline
\end{tabular}

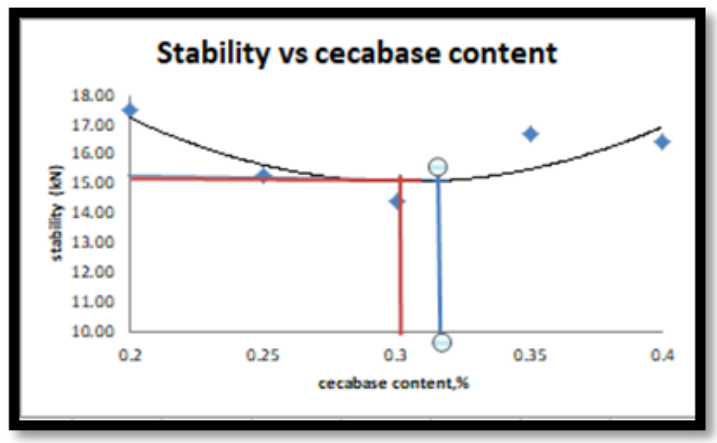

(a)

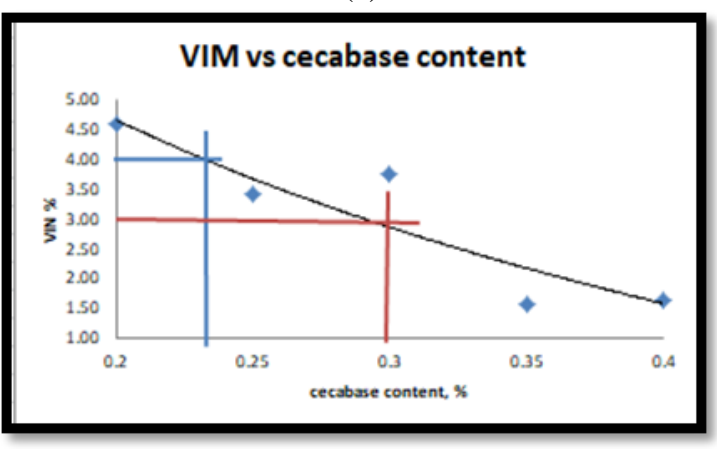

(b)

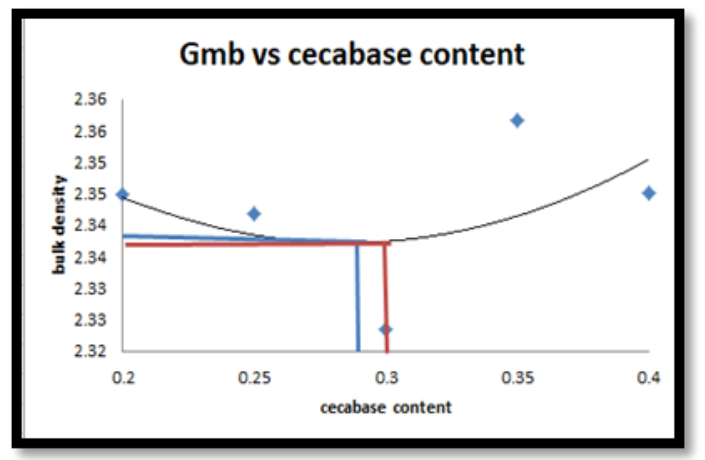

(c)

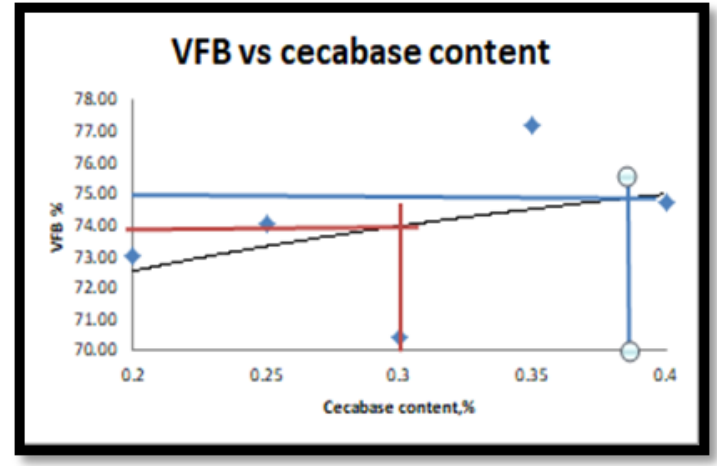

(d)

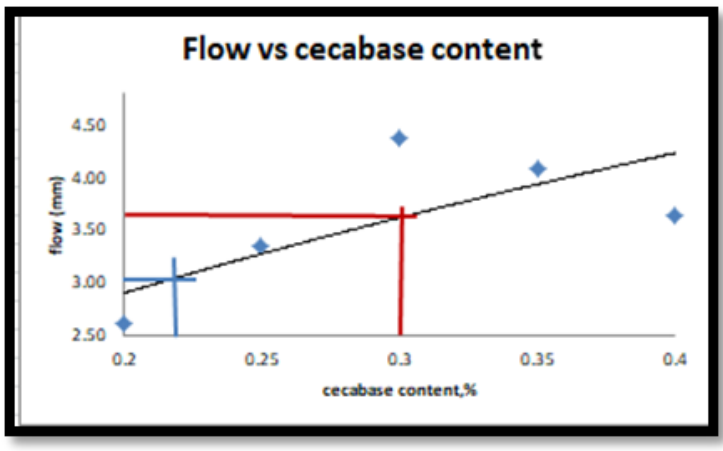

(e)

Fig. 4. Effects of cecabase RT on Marshall Test Results for WMA (Individual plot of cecabase RT content versus (a) Stability, (b) Air void, (c) Bulk density, (d) Voids Filled with Bitumen and (e) Flow

\section{Resilient Modulus}

The resilient modulus test results for pulse repetitive periods of $1000 \mathrm{~ms}, 2000 \mathrm{~ms}$ and $3000 \mathrm{~ms}$ are shown in Figure 5 for test temperature of $25^{\circ} \mathrm{C}$ and Figure 6 for test temperature of $40^{\circ} \mathrm{C}$. The resilient modulus values for all pulse repetition periods for test temperature of $25^{\circ} \mathrm{C}$ are higher than for test temperature of $40^{\circ} \mathrm{C}$. When the pulse repetitive period of $1000 \mathrm{~ms}$ was applied at $25^{\circ} \mathrm{C}$, the value of resilient modulus for control mixture was 5,241 $\mathrm{MPa}$ while $6367 \mathrm{MPa}$ for the WMA mixture. For the $2000 \mathrm{~ms}$ pulse period at test temperature of $25^{\circ} \mathrm{C}$, the resilient modulus values for control and WMA mixes were $5019 \mathrm{MPa}$ and 6183 $\mathrm{MPa}$ respectively. When the $3000 \mathrm{~ms}$ pulse period was applied at test temperature of $25^{\circ} \mathrm{C}$, the values of resilient modulus for control and WMA mixtures were $5174 \mathrm{MPa}$ and $6119 \mathrm{MPa}$. The results showed that the addition of Cecabase RT can improve the stiffness of WMA mixes as indicated with the higher resilient modulus values of the mixes. Similar pattern were observed for the resilient modulus values tested at $40^{\circ} \mathrm{C}$ as shown in Figure 6. 


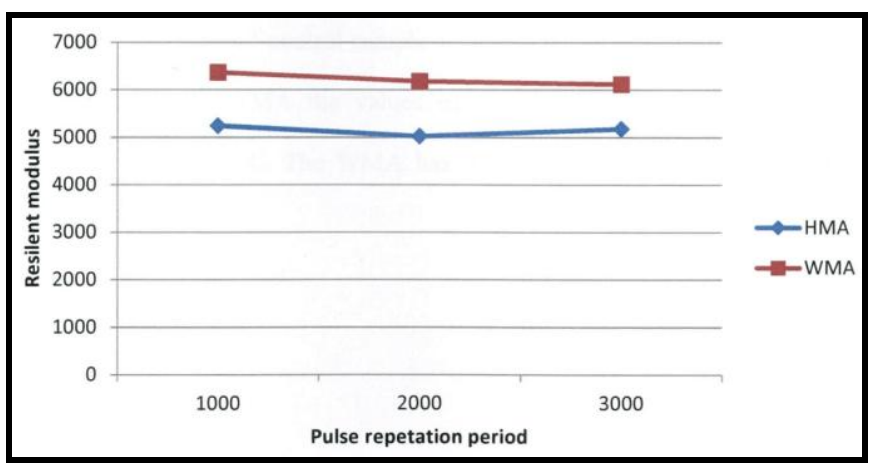

Fig. 5. Resilient Modulus at $25^{\circ} \mathrm{C}$

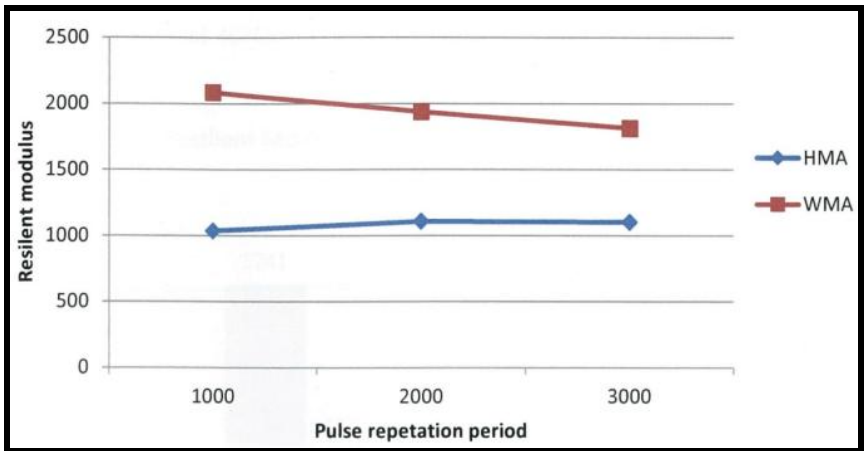

Fig. 6. Resilient Modulus at $40^{\circ} \mathrm{C}$

\section{CONCLUSION}

From this study, it was found that optimum bitumen content was at $4.9 \%$ while the optimum Cecabase RT additive content for the $\mathrm{AC} 14$ mix is $0.3 \%$. The mixing temperature used was $135^{\circ} \mathrm{C}$ while the compaction temperature was $120^{\circ} \mathrm{C}$, which are lower than the temperatures used for conventional HMA mixes. The resilient modulus values obtained for the mix using Cecabase RT warm mix additive is higher than the control samples (without Cecabase RT) at both test temperatures of $25^{\circ} \mathrm{C}$ and $40^{\circ} \mathrm{C}$ and at all pulse repetition periods tested. It can be concluded that the use of Cecabase RT additive has the advantages of reducing the mixing temperature, thus producing a more energy efficient mix while improving the stiffness of the mix in terms of resilient modulus values, thus increasing a pavement load carrying capacity. This study has shown that the use of Cecabase additive can produce asphaltic concrete that is energy efficient, without compromising the performance of the mixes.

\section{ACKNOWLEDGMENT}

The authors expressed utmost gratitude to the Institute of Infrastructure Engineering and Sustainable Management (IIESM), Universiti Teknologi MARA, Shah Alam and the Ministry of Education for the FRGS Research Grant: FRGS/1/2017/TK01/UITM/02/09 which provide the financial support enabling this paper to be written.

\section{REFERENCES}

1. Brown, E.R., Kandhal, P.S., Roberts, F.L. Kim, Y.R., Lee, D \& Kennedy, W., 2004. Hot Mix Asphalt Materials, Design and Construction, 3rd ed., NAPA Reasearch and Education Foundation, Lanham, Marylan, U.S.A.
2. Newcomb, D., 2008. Warm Mix Asphalt - The Future of Flexible Pavements. In: Proceedings of 12th Annual Minnesota Pavement Conference, St. Paul, Minnesota, U.S.A.

3. Manjunath, K.R., Dheeraj Kumar, N. and Thippeswamy, G.S., 2014. Performance and Evaluation on Marshall Stability Properties of Warm Mix Asphalt Using Evotherm and Cecabase RT - A Chemical Additive, International Journal of Engineering Trends and Technology, Volume 12(8), June 2014, pp.406-410.

4. Anderson, R. M. , Baumgardner, G. \& Reinke, G., 2008. Engineering Properties, Emissions and Field Performance of Warm Mix Asphalt Technologies. National Cooperative Highway Research Program (NCHRP,) Transportation Research Board, National Academy Press, Washington D.C.

5. Jones, W., 2004. Warm Mix Asphalt - A State-of-the-Art Review Australian Asphalt Pavement Association Advisory Note 17, KEW Victoria, Australia.

6. Goh, S. W., You, Z. \& Van Dam, T. J., 2007. Laboratory Evaluation and Pavement Design for Warm Mix Asphalt. In: Proceedings of the 2007 Mid-Continent Transportation Research Symposium, Ames, Iowa.

7. Kridan, F.A.M., Arshad, A.K., Rahman, M.Y.A., 2010. Development of warm mix asphalt and compliance with the requirements set by specifications. European Journal of Scientific Research, Volume 48(1), pp. 118-128.

8. Arshad, A.K., Shaffie, E., Ismail, F., Hashim, W., Abd Rahman, Z., 2018. Asphaltic concrete evaluation for mechanistic pavement design, International Journal of Civil Engineering and Technology, Volume 9(8), pp. 513-521.

9. Rondon-Quintana, H.A., Ocampo-Terreros, M.S., Vacca-Gamez, H.A. Reyes-Lizcano, F.A., Nieto-Mora, J.P. \& Beltran-Cruz, D.P., 2016. The mechanical behaviour of two warm-mix asphalts. Ingenieria $E$ Investigacion, Volume 36(3), December 2016, pp. 29-38.

10. Public Works Department of Malaysia, 2008, Standard Specification for Road Works (JKR/SPJ/2008-S4), Kuala Lumpur, Malaysia.

\section{AUTHORS PROFILE}

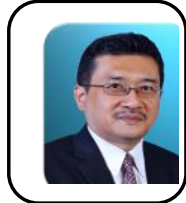

Ir. Dr. Ahmad Kamil Arshad is an Associate Professor at Universiti Teknologi MARA, Shah Alam, Malaysia. He specialises in the field of Highway and Pavement Engineering. He is a Fellow of The Institution of Engineers, Malaysia and has served in various committees for the Institution.

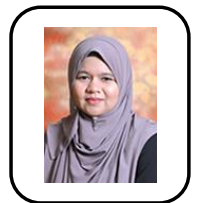

Dr. Ekarizan Shaffie is a Senior Lecturer at Universiti Teknologi MARA, Shah Alam, Malaysia. She specialises in the field of Pavement Engineering.

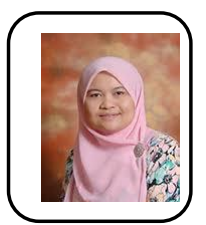

Dr. Wardati Hashim is a Senior Lecturer at Universiti Teknologi MARA, Shah Alam, Malaysia. She specialises in the field of Highway and Traffic Engineering.

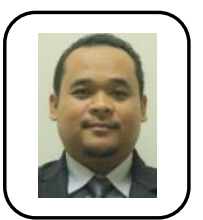

Dr. Khairil Azman Masri is a Senior Lecturer at Universiti Malaysia Pahang. He specialises in the field of Pavement Engineering. 